at pipe emplacement (ii) progressively leached phlogopite fractions from the same separate show a dramatic increase in $87 \mathrm{Sr} /{ }^{86} \mathrm{Sr}$ and $87 \mathrm{Rb} /{ }^{86} \mathrm{Sr}$, consistent with removal of calcite lamelli, but still define an age of $87 \mathrm{~m} . y .$, (iii) whole rock initial ratios are generally lowe1 enan for diopside or K-richterite, (iv) different portions of the same rock are not in isotopic equilibrium (see three circled points joined by a solid line in Fig. 3) and (v) leaching of one whole rock yielded a leached residue with a higher initial ${ }^{87} \mathrm{Sr} /$ $36 \mathrm{Sr}$ ratio $(.70546)$, and a leach solution with a lower initial ratio $(.70503)$ than the original rock (.70525)

Summary of the above suggests that while the major $\mathrm{Rb}$ and $\mathrm{Sr}$ hosts, phlogopite, diopside and $\mathrm{K}$-richterite are in approximate isotopic equilibrium, the rocks analysed also contain (exotic?) components with un-equilibrated strontium. These could be fluids of kimber1ite origin (cf. "secondary" phlogopite selvedges around garnets in GPP rocks) since mixing plots $\left(87 \mathrm{Sr} /{ }^{86} \mathrm{Sr}\right.$ vs $1 / \mathrm{Sr}$ ) show that this is not due to the simple addition of the kimberlite itself. Rocks with lowest $\mathrm{Rb}$ and $\mathrm{Sr}$ would be most affected; least metasomatised GP rock AJE25 [2] has an inital ratio of .70473 while its tiopside has an initial ratio of .70512 , in support of the above contention. Thus, while some samples shown in Fig. 3 may have had their $87 \mathrm{Sr} / 86 \mathrm{Sr}$ ratios decreasef slightly during kimberlite emplacement, the overall scatter is considered to be a consequence of mantle metasomatism which has affected all the peridotites analysed. This is emphasized by diopside analyses, which show high and variable ${ }^{87} \mathrm{Sr} / 86 \mathrm{Sr}$ ratios (Fig.4) and $\mathrm{Sr}$ contents, 200-1000 ppm Sr [2]. The metasomatic fluids appear to have had variable $87 \mathrm{Sr} / 86 \mathrm{sr}$ ratios and $\mathrm{Sr}$ contents and while it is possible to infer a chemical distinction in terms of $\mathrm{Rb} / \mathrm{Sr}$ between the garnetbearing and garnet-free peridotites, no clear distinction can be made regarding the timing of metasomatic event (s). The significance of the $150 \mathrm{~m} \cdot \mathrm{y}$. reference line in Fig.3, considered[2] to be related to the cessation of Karoo igneous activity, remains an open question, and must be viewed in context with the Nd-isotop lata presented in Fig. 4.

The $143 \mathrm{Nd} / 144 \mathrm{Nd}$ data confirm the enriched nature of the neridotites, consistent rith previous iata for peridotite diopsides [3], compared with present day Bulk Earth (intersecting lines in Fig.4), kimberlites [4, this study] and diopside megacrysts [4]. The lower $143 \mathrm{Nd} / 144 \mathrm{Nd}$ ratios of peridotite diopsides, reporter as being separates from the GPP group, with respect to the PKP rock data for a given ${ }^{87} \mathrm{Sr} /{ }^{86} \mathrm{Sr}$ value (Fig. 4 ), might suggest that the former indicate an earlier metasomatic event than inferred for the PKP data, bas ed on consideration of Nd model ( $\mathrm{CH}$ IR) ages. However, the most "enriched" diopside has now been found to be

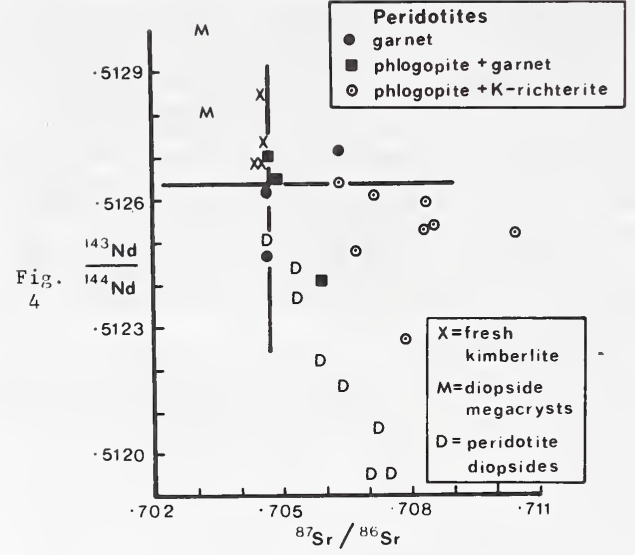

from a PKP, and not a GPP, rock. $143 \mathrm{Nd} / 144 \mathrm{Nd}$ data for this rock, two other GPP rocks and associated diopside and mica analyses [3] are as follows :

\begin{tabular}{|c|c|c|c|c|}
\hline Sample & Type & Rock & Diopside & Phlogopite \\
\hline CK26 & GPP & $.51265 \pm 2$ & $.51223 \pm 2$ & $.51185 \pm 7$ \\
\hline CK27 & GPP & $.51270 \pm 2$ & $.51250 \pm 3$ & $.51224+10$ \\
\hline CK32 & PKP & $.51227 \mp 1$ & $.51195+4$ & $-{ }^{-}$ \\
\hline
\end{tabular}

The implied disequilibrium, together with the proximity of CK26 and CK27 to the kimberlite data (Fig.4) suggest that, as with $\mathrm{Sr}$, the whole rocks contain unquilibrated Nd of kimberlite origin. Nevertheless, the relatively low $143 \mathrm{Nd} / 144 \mathrm{Nd}$ ratios in rock CF32, coupled with the even lower ratios in its diopside (and the phlogopites), suggest an earlier age of metasomatism than indicated by the sr-isotope data, and it is possible that rock C.K32 may contain two mantle metasomatic age components. More detailed isotopic work is clearly required before the timing of mantle metasomatism and the mantle differentiation events (melting, plume act ivity, subduction) possibly involved in the nroductior of the metasomatic fluids, can be defined.

References : (1) Erlank, A.J. and Rickard, R.S., 1977: Ext. Abst., 2nd Int. Conf. Kimherlites, Santa Fe. (?) Erlank, A.J. and Shimizu N., $1977:$ Fxt. Ahst., 2nd Int. Conf. Kimberlites, Santa Fe. (3) Menzies, M.A. and ilurthy V.R., 1080: Nature 283, 634-636. (4) Kramers, J.D., Smith, C.B., Lock N.P., Harmon R.S., and Boyd, F.R. 1981: Nature 291, 53-56.

\title{
VOLUME INSTABILITIES IN THE MANTLE AS A POSSIBLE CAUSE FOR KIMBERLITE FORM
}

\section{Friedemann FREUND}

Mineralogisches Institut, Unovrsität zu Köln Fed. Rep. Germany

The occurence of kimberlites and their mode of formation are evidence for punctual instabilities in the mantle which lead to the buildup of extremely high fluid pressures in an alkali-rich, mostly potassic environment. The peolopical settinp points at the mantle underneath stable shields. The drivinp force is provided mainly by $\mathrm{CO}_{2}$ with additional $\mathrm{H}_{2} \mathrm{O}$, but the ases contained in fluid inclusions, for instance in diamonds, are varied. They comnrise hydrocarbons, alcohols, oxygen, nitrofen, and others.

In order to understand kimberlites and kimberlite formation it is essential to pain an insioht into the aynamic nrocesses which occur under the confinine pressure of the mantle. Obviously these processes are related to the presence and to the local accumulation of dissolved fluid phases. Hence, it is important to understand their dissolution mechanism, to know what solute species mifht form and what their role could be in the temporal evolution of a potential kimberlite source repion.

The usual approach followed by retrolorists is to analyze the phases present in a given rock and to relate these findinfs to experimental data from hioh pressure laboratory studies. It is well known that carbonates and hydroxylbearing phases orecinitate from $\mathrm{CC}_{2}-$ and $\mathrm{H}_{2} \mathrm{O}_{-}$ rich magmatic systems. It has therefore been concluded that carbonate jons, $\mathrm{Cn}_{3} \mathrm{C}^{-}$, and hydroxyl ions, $\mathrm{OH}^{-}$, are the prevailent solute species. This view has recently been challenped (FREUND 1981 a and references cited therein) by the discovery of solute carbon in synthetic MpO and in natural, mantle-derived olivine which is not carbonate but a novel carbon species characterized by a valence state near zero and by a srecial nature of the chemical bond with the surrounding oxjrens. The name "atomic carbon" has been coined for such dissolved carbon species which formally derive from the $\mathrm{CO}_{2}$ dissolution mechanism.

The "atomic carbon" dissolved in oxides and silicates has unusual properties, both chemical and physical unlike any carbonate carbon. The "atomic carbon" is capable of reactinf. with the lattice oxypen to pive $\mathrm{CC}_{2}$ or $C \mathrm{C}$ depending on experimental parameters. With the hydrogen derived from lattice-bound $\mathrm{OH}^{-}$, i. e. from the dissolution mechanism of $\mathrm{H}_{2} \mathrm{O}$, this carbon re- 
acts to pive a wide variety of hydrocarbons, saturated and non-saturated, including aromatic compounds. With molecular $\mathrm{H}_{2} \mathrm{O}$ it reacts to give alcohols; with co-dissolved nitropen to ive $\mathrm{HCN}$, amines, and other complex $\mathrm{C}-\mathrm{N}$ compounds. With the silicon of the silicates it may form $\mathrm{Si}-\mathrm{C}$ bonds. With the cations, for instance with $\mathrm{NF}^{2+}$ and $\mathrm{Fe}^{2+}$ in olivines, it reacts to give volatile metal-bearino orpanic compounds (FREUND et al. 1982).

The physical properties of the "atomic carbon" are equally outstandine and in sharp contrast to what one would expect for carbon from carbonate ions.

The diffusion of the "atomic carbon" is extremely fast even in such densely packed structures like Mpo and olivine. The diffusion coefficient data which are now available cover the temperature range from $-100^{\circ} \mathrm{C}$ to $700^{\circ} \mathrm{C}$ WEINGELER et al. 1982; KATHREIN 1982; KATHREIN et al. 1982; OBERHEUSER 198?). They indicate that the "atomic carbon" may be the fastest diffusinf species in mantle rocks. Its motion is endowed with a nerative activation volume of diffusion. This is nothin else but the mathematical expression for the fact that the $\mathrm{CO}_{2}$ dissolution increases with hydrc static pressure (BROWN and ASFBY 1980). Indeed, the $\mathrm{CO}_{2}$ solubility rocks, both solid and liquid, increase quite dramatically above $10-20 \mathrm{kbars}$, corresponding to a depth range of $30-60 \mathrm{~km}$, i. e. to the lower crust and/or upper mantle. At the same time, however, "atoric carbon" diffuses in response to stress, both ricroscopic and macroscopic, from refions of hirh stress to refions of low stress. Frain bourdaries represent no diffusion barriers for the "atomic carbon", because it can convert reversibly to $\mathrm{CO}_{2}$ and back to dissolved carbon at the prain-to-prain interface.

By combinine the available physicochemical data with the peneral concept of plate tectonics we are led to consider lon rrange carbon diffusion as a very realistic reological possibility. This carbon diffusion is expected to occur at or below the crust/mantle boundary from refions of hiph compressive stress to repions of tensile stress or stress shadow zones. It may transnort a large flux of "atomic carbon" over distances of hundreds or thousands of kilometers within, feolopically speakin, short to moderately lon $p$ times.

the nature of the "atomic carbon" cannot be fully anprehended, unless one understands the process of charpe transfer (CT) hy which carbon becomes reduced to the essentinlly ze rovalent state and oxygen becomes oxidized from the $0^{-}$state to the $0^{-}$state (FREUIn $1981 \mathrm{~b})$. Any $\mathrm{O}^{-}$represents a defect electron in a river oxide or silicate structure. This tate is the companion of the "atomic carbon" and remains associated with it durinf diffusion. The $\mathrm{C}^{-} \mathrm{C}^{-}$bond is quite energetic, stronfly covalent but at the same time spatially delocalized. This is kecause every neiphboring $\mathrm{O}^{2-}$ can become an $\mathrm{O}^{-}$by a mere electron exchange. Thus, when the "atomic carbon" diffuses, defect electrons travel along, probably two per $C$ atcm. In a very schematic way we may represent this as follows:

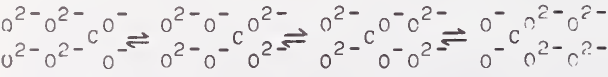
(1)

During steps $1 / 2$ and $3 / 4$ two electrons move from left to right while the c atom executes one diffusional jump from ripht to left between step $2 / 3$

Thus, durinf the postulated long-range diffusion of "atomic carbon" an electron flux of equal mapnitude is anticipated to occur in the opposite direction. If the "atomic carbon" accumulates in a piven stress shadow zone somewhere in the mantle, this also means an accumulation of $0^{-}, i$. e. of defect electrons.

The $0^{-}$, if taken separately, are canable of formin dimers, trimers and possibly tetramers which are resonance-stabilized to various defrees through their interaction with the sur roundinp $\mathrm{O}^{-}$and with the atomic $C$. When the $r, T-c o n d i t i o n s$ change in a certain way such as expected for a diapiric uplift environment, hoth experimental data (KATHREIN 1932) and theoretical considerations indicate that the stabilization breaks down. Such a breakdown is accompanied by an efflux of defect electrons, because the $0^{-}$then tend to reconvert to $0^{2-}$. One of several possible consequences of this process is an influx of electrons from the surrounding mantle to account for the $0^{-} \rightleftharpoons 0^{2-}$ conversion.

In such a case the mantle volume under consideration will (a) increase in volume, besiderably lareer than that of the $0^{-}$, and (b) acquire a differential negative charre due to the electron influx. As a result of the latte positive charfes, viz. cations, will be drawn in concomitantly in order to maintain electroneutrality.

This process is essentially electrochemical. We propose to call it "electrochemically driven metasomatism". Depending upon the nature and the availability of the positive charees in the surrounding mantle and/or in the overlying crust the cation influx can be either predominantly $\mathrm{H}^{+}, \mathrm{Na}^{+}, \mathrm{K}^{+}$. In any case the relting temperature will decrease, probably to a dramatic extent. The volume will increase. The pressure, both internal and that exerted on the surrounding rock, will rise. The ultimate consequence of this process is anstability in the mantle which is selfcatalyzing and self-amplifying (FRF,UND 1981c). If an electrochemically driven metasomatosis as outlined here develops deep in the mantle where $\mathrm{K}^{+}$dominates, a kimberlitic mapma can be penerated. It is expected to propapate towards the surface of the Earth. Durinf the depressurisation the charce transfer (CT) processes which provide the basis for $0^{-}$formation and their reconversion to $\mathrm{O}^{2-}$ will becore accelerated. As soon as $\mathrm{CO}_{2}$ ras forms, two electron per $\mathrm{CO}_{2}$ molecule are released. The final stage is an explosive discharfe of the hiphly potas sic, $\mathrm{CO}_{2}$-driven mapma. This magma is expected to be in an unusual nhysical state best described as plasma-like, adiabatically cooled, but characterized by electronic CT processes which are still in propress in the fluidized solid and which will eventually be quenched ty an influx of $\mathrm{HI}^{+}$from meteoritic water leadinf to a late-stage serpentinisation.

In summarizing we can say that the mechanism of kimberlite formation and eruption outlined here derives from a mechanism - novel for feolofy - of interatoric electronic charfe trars fer (CT) occuring in solids as a function of $P$ and $T$ between oxygen as electron donor and electropositive electron as acceptors. Its backpround is well-founded theoretically since a long time and it has been studied in detail experimentally for the $\mathrm{CO}_{2}$ and $\mathrm{H}_{2} \mathrm{O}$ solubility in $M F C$ and in mantle-derived silicate minerals such as olivine. The attractive feature of the CT mechanism and of its sequential evolution through various stapes is that it leads to an entirely novel concent of mapma penesis without violating, at any step, known physicochemical principles. The kimberlite marma penesis represents an extreme case.

BKOWN A.M. and ASHBY $M$.

Correlations for diffusion constants

Acta Metall. 28 1085-1101

FREUND F. (1981a):

Mechanism of the water and carbon dioxide solubility in oxides and silicates and the role of 0

Contrib. Mineral. Petrol. 76 474-482

FREUND F. (1981b):

Charpe transfer and $\mathrm{O}^{-}$formation in hieh and ultrahioh pressure phase transitions Bull. Minéral. 104 177-185

FREUND F. $(1981 \mathrm{c})$ :

Deep-seated instabilities in the mantle Terra Copnita $188-89$ (Abstract)

FREUND F., KNOBEL P.M., WENCELER H., KATHREIN H., and SCHAEFER R.G. (198?): 
Orfanic compounds in the early atmosphere formed abiotically from atomic carbon

(ieol. Rundschau 71 1-21

KATHRFIN, H. (1982):

Structures and properties of defects in magnesium oxide associated with carbon and hydrogen

Ph. D. Thesis Univ. Cologne (in German)

KATHREIN H., GONSKA H., and FREUND F. (1982): Subsurface segrefation and diffusion of carbon in magnesium oxide
J. Appl. Phys. (A) accepted for publication OBERHEUSER G. (1982):

Carbon, excess oxygen and $\mathrm{OH}^{-}$ions in olivine single crystals

Ph. D. Thesis Univ. Cologne (in German)

WFNGELER h., KNOBEL R., KATHREIN H., FREUND F., DEMOPTIEF G. and WOLFF G. (1982):

Atomic carbon in mapnesium oxide single crystals - depth profiling, temperature and time-dependent behavior

J. Phys. Chem. Solids 43 59-71

H14

\section{METASOMATISM IN THE MANTLE BENEATH PIPE 200, NORTHERN LESOTHO}

\section{E.S. SCHANDL,}

Dept. of Geological Sciences, McGill University, Montreal, P.Q., Canada

D.B. CLARKE,

Dept. of Geology, Dalhousie University, Halifax, N.S., Canada

\section{Introduction}

Peridotite nodules in kimberlite contain information about the equilibria or disequilibria that prevailed in the mantle just prior to eruptio If a nodule shows signs of physical (textural) or chemical disequilibrium, then information may potentially be obtained on two or more processes which had affected the mantle in the vicinity of its origin, including the timing of those events. This is the case with a small number of nodules from Pipe 200, including some described by Carswel et al. (1979) and Mitchell et al. (1980).

The Pipe 200 (PTH) nodules consist of garnet therzolite, garnet-chromite lherzolite, chromite lherzolite and spinel harzburgite. The rocks generally have low modal percentages of clinopyroxene and garnet, low $\mathrm{Al}_{2} \mathrm{O}_{3}, \mathrm{CaO}$ and $\mathrm{Na}_{2} \mathrm{O}$, high $100 \mathrm{Mg} /(\mathrm{Mg}+\mathrm{Fe})$ values of $91.0-95.4$ and high 100 $\mathrm{Cr} /(\mathrm{Cr}+\mathrm{Al})$ values of 11.6-48.9. These features are consistent with depletion caused by removal of a basaltic partial melt from more normal garnet lherzolite.

\section{Mineralogy and Chemistry of the Altered Samples}

Six different peridotite nodules (PTH 108, 202 204 and 404 of Carswell et al (1979), plus PTH 58 and 516 courtesy of B. Harte and M.J. O'Hara) were the subject of further study because of their unusual mineralogy and the textural associations

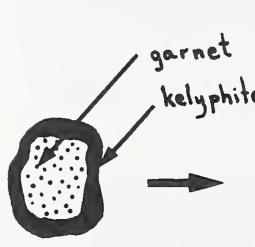

A

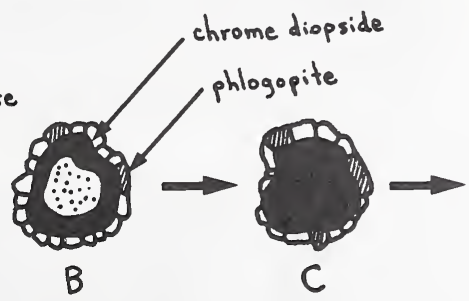

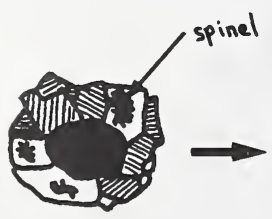

D

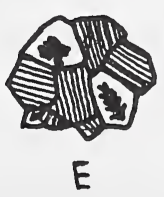

Figure 1

\section{$2 \mathrm{~mm}$}

involving those minerals. Normal PTH nodules contain some chrome pyrope garnet, usually with a rim of fine-grained kelyphite attributable to rapid alteration in the ascending kimberlite (Fig. 1A). In sample PTH 58 chrome diopside occurs as rare discrete grains in the rock, but more significantly as a collar of grains, with clear cores and cloudy, pitted margins, around the garnets. This collar also contains small amounts of phlogopite and tiny euhedral spinels. The garnet may be partially kelyphitized (PTH 58, Fig. 1B) or wholly kelyphitized (PTH 404, Fig. 1C). In sample PTH 204 (Fig. 1D), the collars around a kelyphitized garnet core are considerably wider, coarser grained, and both phlogopite and spinel are more abundant.

The clinopyroxene and phlogopite show a mosaic

PTH 58 (COLLAR)

\begin{tabular}{|c|c|c|c|c|c|c|}
\hline & $\underline{\mathrm{CPX}}$ & PHL & $\underline{\mathrm{SP}}$ & $\underline{\mathrm{CPX}}$ & $\underline{\mathrm{PHL}}$ & $\underline{\mathrm{SP}}$ \\
\hline $\mathrm{SiO}_{2}$ & 55.22 & 41.16 & - & 54.51 & 40.26 & - \\
\hline $\mathrm{TiO}_{2}$ & - & 0.29 & 0.96 & - & 0.22 & - \\
\hline $\mathrm{Al}_{2} \mathrm{O}_{3}$ & 2.52 & 13.18 & 9.45 & 4.45 & 14.92 & 14.8 \\
\hline $\mathrm{Cr}_{2} \mathrm{O}_{3}$ & 2.95 & 1.03 & 54.08 & 3.10 & 1.11 & 53.7 \\
\hline $\mathrm{FeO}$ & 2.04 & 2.60 & 18.94 & 1.99 & 2.31 & 18.0 \\
\hline Mno & - & - & 0.16 & - & - & - \\
\hline MgO & 15.95 & 25.00 & 13.20 & 13.60 & 24.22 & 13.6 \\
\hline $\mathrm{CaO}$ & 19.06 & - & 0.10 & 19.95 & - & - \\
\hline $\mathrm{Na}_{2} \mathrm{O}$ & 2.61 & 1.16 & - & 3.29 & 0.80 & - \\
\hline $\mathrm{K}_{2} \mathrm{O}$ & - & 9.80 & - & - & 9.83 & - \\
\hline OTAL & 35 & 94.22 & 96.89 & 100.89 & 93.67 & 0.10 \\
\hline
\end{tabular}

PTH 108 (POOL)

\begin{tabular}{|c|c|c|c|}
\hline & $\mathrm{CPX}$ & PHL & $\underline{\mathrm{SP}}$ \\
\hline $\mathrm{SiO}_{2}$ & 54.31 & 42.48 & - \\
\hline $\mathrm{riO}_{2}$ & - & 0.23 & 0.73 \\
\hline $1_{2} \mathrm{O}_{3}$ & 1.28 & 12.38 & 5.35 \\
\hline $\mathrm{r}_{2} \mathrm{O}_{3}$ & 3.11 & 0.88 & 59.90 \\
\hline eO & 2.37 & 2.71 & 22.61 \\
\hline no & 0.11 & - & 0.55 \\
\hline g0 & 16.46 & 26.49 & 11.10 \\
\hline & 20.53 & - & - \\
\hline & 2.14 & - & - \\
\hline & - & 10.03 & - \\
\hline
\end{tabular}

TOTAL $100.31 \quad 95.20 \quad 100.24$

Table 1. 